\title{
Technology's Winding Path: Implications for South African Development
}

\author{
K. R. Kemm* \\ Stratek: Technology Strategy Consultants, P.O. Box 74416, Lynnwood Ridge, 0040, Pretoria, South Africa
}

Received November 11, 2000; revised version received March 26, 2001; accepted May 14, 2001

PACS Ref: 01

\begin{abstract}
Technology is more and more becoming the fundamental wealth creation mechanism of any country. Therefore national skill in technology application is essential for competition in the international economy.

The speed of technological change makes control of technology all the more difficult particularly for developing countries. However, an important consideration is that technology is not only a technical discipline, but relies heavily on the marketability and social acceptability of the final product. This concept demands a multidisciplinary approach across widely divergent disciplines. Scientists should be at the forefront of promoting and driving multidisciplinary technology decision-making and implementation.
\end{abstract}

\section{Introduction}

Technology is a subject that creates a great aura of mystery around it. There are various reasons for this frame of mind that range from the fact that technology is undoubtedly a difficult enterprise conducted by highly skilled people, to the fact that the general public don't understand most of the technological devices and systems that enter their daily lives. The concept of technology is seen by the public as a technical activity only, which it is not. However this narrow view of technology is not only the domain of the general public, but is also an opinion shared by many managers in business and industry.

This limited vision of technology is particularly evident when high technology is considered. Furthermore, this view is more dominant in developing countries when both high and low technology are considered.

This all implies that often in developing countries technology is seen as a high-powered activity that is carried out by others in the sophisticated first world countries. This opinion no doubt means that many opportunities for technology advancement in developing countries are lost as people view the endeavour as something not meant for them [1].

\section{Technology - what is it?}

Before pursuing these considerations of technology and its role in various societies it is instructive to ask the question: What is technology?

The following approach to a definition of technology is used:

The written definitions of technology found in academic papers are wide and varying [2]. Perhaps this fact signifies the complexity of the concept. The author is of the opinion that it is not possible to write down an acceptable definition of technology in words, bearing in mind that a definition should be concise. Instead, a picture is needed, but a picture is worth a 1000 words!

Some persons feel that it is not possible to make the statement that a definition of technology cannot be written in words, but as a comparison consider the concept of love. All people believe that they know what love is, but no universal definition of love exists despite the endeavours of writers such as Shakespeare, and philosophers like Plato and Aristotle and the many who followed.

Consider the diagram (Fig. 1) in which the three vertices are Science, Economics and Policies.

And now for a fairy tale ...

Imagine a fairy tale situation in which a homeowner discovers that his garden wheelbarrow is rusting, and so approaches a pure scientist to ask for a solution. The scientist uses totally correct scientific principles and advises the homeowner to gold plate his wheelbarrow! Nobody instructed the scientist to come up with an economically viable solution. So his purest answer was at the $\mathbf{S}$ vertex of the Technology Triangle.

The horrified homeowner asks him to think again, and the scientist proposes a second best, third best option and so on until they arrive at an economically viable solution - they decide to paint it! This solution is now represented by a point

\section{TECHNOLOGY TRIANGLE}

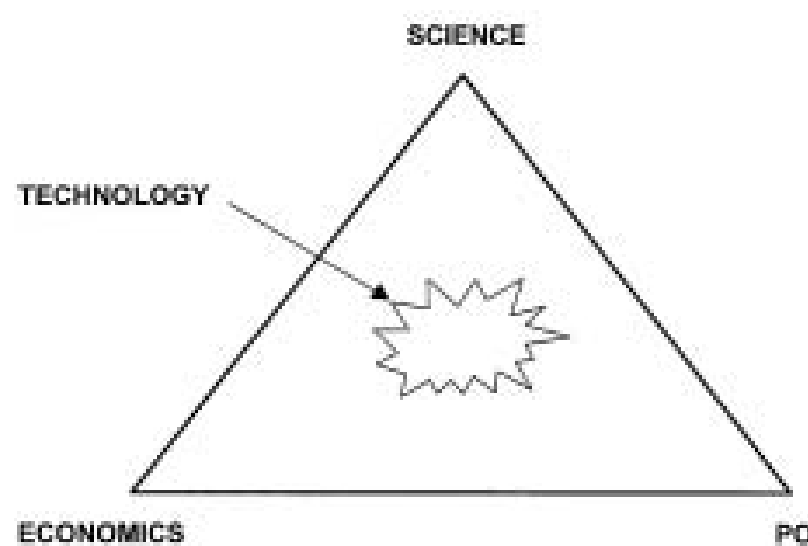

POLICIES

*E-mail: stratek@pixie.co.za

Fig. 1. Technology Triangle. 
somewhere in the middle of the triangle where both the $\mathbf{S}$ and E balance out.

So where does the $\mathbf{P}$ for Policies fit in? This stands for the rules that society imposes, in other words, $\mathbf{P}$ also indicates the People element. The $\mathbf{P}$ indicates such issues as safety regulations, quality standards requirements, health regulations, import/export policies and practices etc.

Continuing our analogy of the wheelbarrow, it is also quite legal to paint a wheelbarrow, the process violates no laws or accepted procedure in the marketplace.

This solution to the wheelbarrow problem is an example of technology. Although it has been stated that it is impossible to write down an adequate definition of technology in words, but that a picture is required, we can nevertheless create a simple word definition which can be stated as long as it is read in conjunction with the picture.

Simply stated, this definition says:

Technology is Science that makes Money within the bounds of the Law.

Put another way, technology is the economically viable and socially acceptable application of science to the benefit of the economic process.

So when the $\mathbf{S}, \mathbf{E}$ and $\mathbf{P}$ all exert their magnetic push and pull on a set of possible solutions to a problem, the final technological answer is one which is Scientifically possible, is within the Policies and Regulations formulated by People, and which at the end of the day is Economically viable, makes a Profit for the company, and so ads to the GDP of the nation.

It must also be noted that technology is not only hardware, it is also process. A smarter way of doing things, a shorter process, a less complex process, these are also all technology improvements leading to increased profits.

What all of this tells one is that technology, and particularly technology strategy, is a Boardroom issue. Technology is not something carried out down in the lower ranks by the "engine room people," who wipe their hands on greasy rags. It is Boardroom strategy. If not, then the speed of change will beat the Boardroom.

This definition of technology implies that technology decisions must be taken by multi-disciplinary teams, or at least in a multidisciplinary mode of thinking.

Note that as per the definition used one must emphasise a distinct difference between technology and science. Technology includes aspects such as economics, law, marketing etc.

\section{Hi tech and Lo tech}

In considering Hi tech and Lo tech, it is important to ponder what these terms really mean, particularly in a developing world context. Also it is important to add the term Appropriate Technology.

First let us consider the term "Appropriate Technology," which has been in use for some years. This term is generally used to mean that first world countries or first world project groups should pass technology down to unsophisticated people, and that the technology should be "appropriate" for their lower level needs or educational standards. In this mode the term can be offensive and it is the author's opinion that it should not be used in this way.

Instead the term "appropriate" should be used to mean that the appropriate level of technology should be applied in each situation - whether it be Hi tech or Lo tech or any combination thereof. In the same vein high tech should not be seen as a higher order of low tech, but rather as one of the array of options. Also, as discussed with reference to the definition, a technology solution could be "high tech" with a low level of science complexity but with a high level of economics and marketing sophistication, for example. So a reference to Hi tech or Lo tech should not be made solely on the basis of the complexity of the science component.

Many proposed technology solutions are successful or otherwise, mainly as a result of the non-technical factors, so to judge a technology on the basis of science alone is short-sighted. It is also important to note that one or more Lo tech options can form very important aspects of extremely sophisticated projects.

It is also the case that Lo technology is at times referred to as "primitive technology." This is incorrect and gives a false image: it does not indicate that a sophisticated project can be made up intentionally of a mix of $\mathrm{Hi}$ and Lo tech.

In Fig. 2 a symbolic large-scale project is indicated in which the "project mix" is an intentional combination of high technology and low technology components. Such a mix would give optimum performance within the cost constraints.

\section{Problem analysis}

It is axiomatic that a problem that presents itself needs to be analysed, but it is constantly surprising how frequently this important function is either not done, or is done badly.

A problem is usually a social problem - in that the reason why any problem exists is because people need an answer. This then means that to address such a problem needs a multidisciplinary approach. Many "engineering" problems

\section{PROJECT MIX}
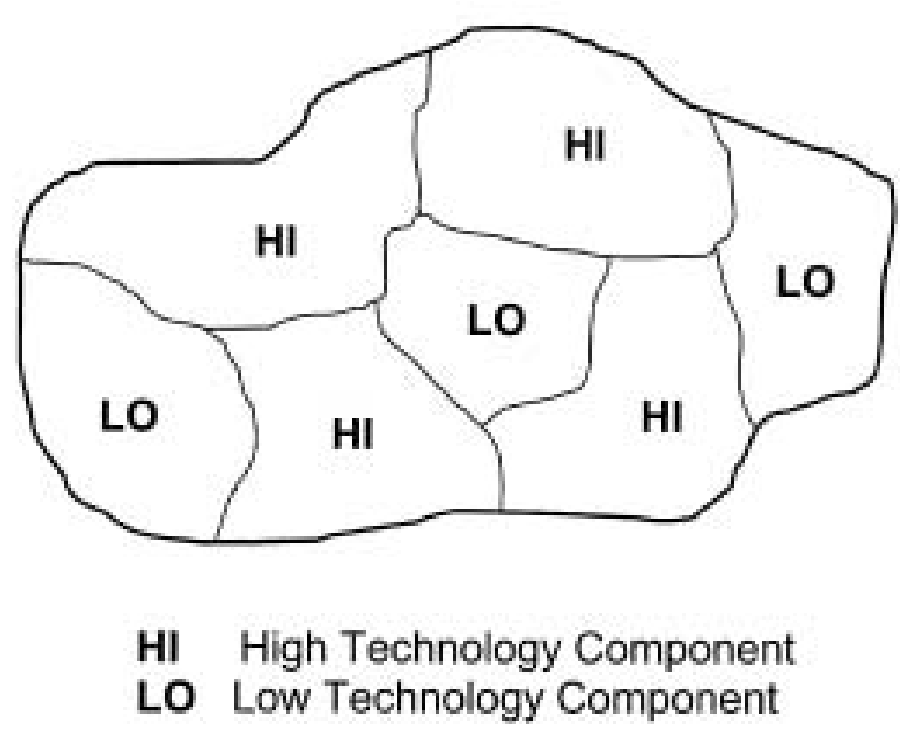

Fig. 2. Project Mix. 
have significant social factors disguised into them, for example: how to reticulate water to a remote rural area. Such a water problem in a third world country can include issues such as finding out that the proposed route, as determined by planners using modern maps, in fact goes through the ancient burial grounds of indigenous people.

To "Problem Solve" needs a multidisciplinary team approach. Out of such an analysis a set of science-based tasks (and other tasks) will emerge. It is important to note that these tasks are not "the problem" but are a subset of the problem.

In Fig. 3 an initial problem (with ill-defined boundaries) undergoes a multidisciplinary problem analysis to generate a set of tasks to be individually tackled.

Undoubtedly scientists can form part of the problem-solving team, but in this mode their thinking is different to that when they are part of the task team. Sometimes subject specialists tend to want to force their own subject speciality onto the problem-solving team as the correct solution when in fact they should be approaching the problem with an open mind [3].

Individual scientists can be part of both the problem-solving team and one or more of the task teams, but the thinking approaches in each case are different. If a scientist is not able to switch his/her mind from the one mode to the other then he/she should stay with the one function only.

\section{Projects and tasks}

It is important to distinguish between:

A Problem Solving, and

B Advancing a new line of Technology.

In the case of $\mathrm{A}$, an example would be: Why do the gearboxes of vehicles in a particular open cast mine fail well before the specified engine-hours lifetime?

\section{APPROACH TO PROBLEM SOLVING}
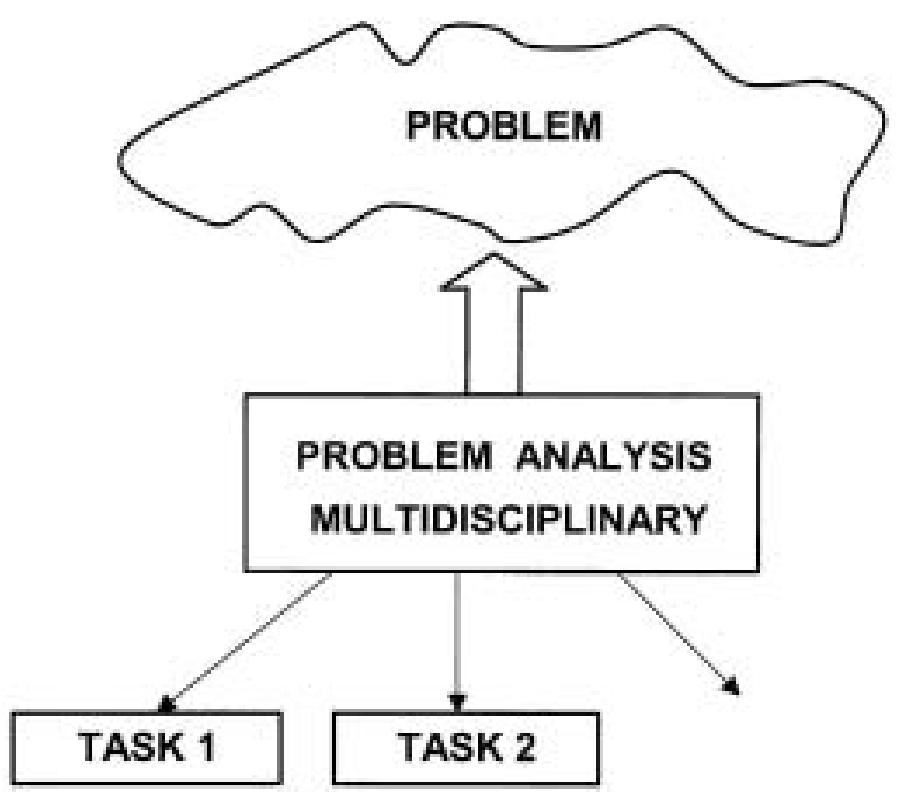

Fig. 3. Approach to Problem Solving.
An example of B would be: Introduce lead-free printing ink into a food packaging plant.

In the case of A, the concept used is that of the "problem" being analysed into a number of tasks to be executed. In B, reference is made to projects. The term project implies a much greater degree of control over the timeframes and the way in which the job can be laid out. A task often has its timeframe decided for you as a consequence of the reality of the business. Also, since a task has to be approached in a Sherlock Holmes detective mode, frequently the approach is somewhat dictated by what is known or what information or access is immediately available.

\section{Speed of change}

Real time industrial technology development and adaption invariably does not have the luxury of unpressured time constraints, as is the desired situation with academic research in a laboratory investigation [4].

In Table I the modern speed of technology change is illustrated. The table indicates the time taken from the discovery of the basic physics of the system to the commercial implementation of that system. With telephony it was the working lifetime of a person, but today a single person's working lifetime covers a variety of new innovations.

In the case of industrial speed of change it is usually money that dictates the speed. In the case of technology adaption, it is frequently the competition which dictates the speed of adaptions [5]. Companies usually have no option but to adapt rapidly when their business competitors introduce new products into the marketplace. It is interesting to note the comment of the world famous Formula One racing driver, Mario Andretti!

\section{If everything is under control then you are not travelling fast enough.}

Mario Andretti, Formula One Racing Driver.

\section{Public perception}

It is important to note the increasing role that public perception is playing in technology development [6].

In the advertising industry it is well known that perception is reality. If the public catch on to an idea that some chemical is dangerous, or cell phone radiation causes brain tumours, then the resulting public pressure becomes a major issue in determining the progress of the technology, even if the public opinion is wrong or irrational [7]. This public opinion aspect falls into the Policies vertex of the Technology Triangle in Fig. 1.

Table I. Time taken to develop product to its commercial exploitation. from the understanding of the basic physical phenomena.

\footnotetext{
112 years for Photography

56 years for telephony

35 years for Radio

12 years for TV

3 years for the Transistor

Approximately 3 years for engineering plastics
} 


\section{THE FACT / EMOTION BALANCE}

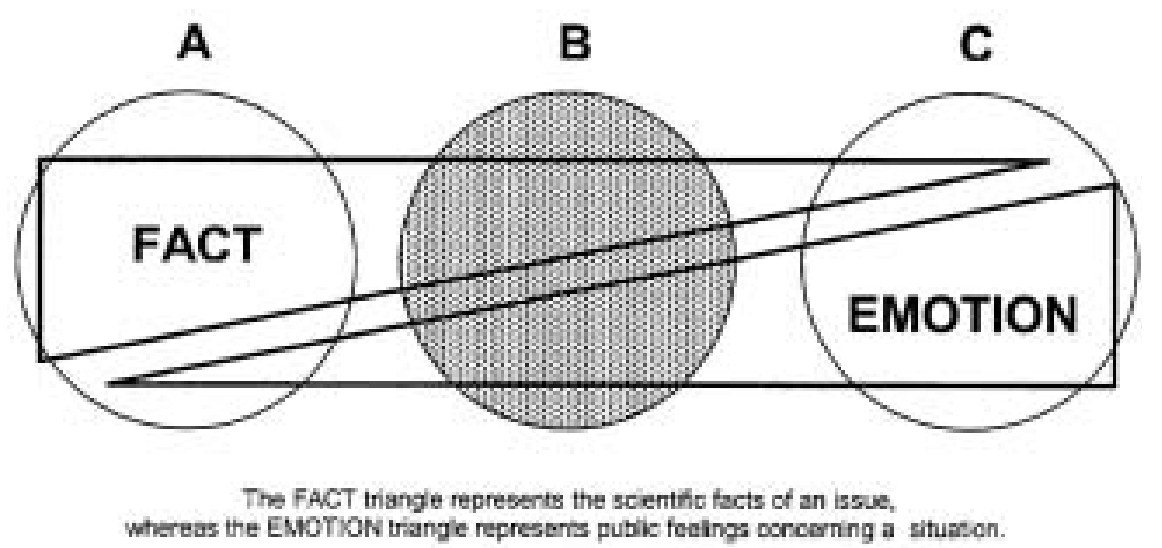

Circle C represents the ivitial p.tolic reaction to a shation, generaly high in emoticn and with litte real grasp of the facts.

Circle $A$ represerts the frequert scentfic response to the sliustion. a colection of tochnical facts preserted wish lese regerd to puefic percepticns.

Circle B represerva the respense that sclectiss should presert to the public sufficient factis but bslanced wth an understanding of the fears and perceptions of the isyman.

Fig. 4. The Fact/Emotion Balance.

Figure 4 illustrates the public Fact/Emotion balance. Frequently a scare story that is lacking in fact, but is high in emotion gets featured in the press, such as a claim that some chemical food additive is maybe potentially harmful to pregnant mothers. The public reaction occurs in the right hand circle of Fig. 4, high emotion with minimal care for the facts. Invariably professional scientists then publicly respond entirely in the left-hand circle - they produce documents for the press that consist of pages of scientific fact or computer printout, material that is highly factual, but has almost zero human content.

What is required is a response from scientists in the Centre Circle, in other words enough fact to support the argument, but also enough of a response that means something in the day to day layman's frame of reference.

\section{Conclusion}

Einstein said that common sense is that collection of prejudices and misconceptions that you pick up by the age of eighteen.

The application of technology is ultimately a money-making exercise, and one must take care to ensure that a variety of science "common sense" issues do not destroy or undermine the overall technology endeavour.
Technology application is a multidisciplinary enterprise which needs careful planning and should not be clouded by scientists promoting only their "common sense" approach.

On the other hand technology projects and technology decisions should not be formulated without significant science input. All too often governments or company decision-making bodies make major technological decisions without the adequate participation of suitably skilled scientists. [8].

\section{References}

1. Kendall, F. and Louw, L., "Let the People Govern" (Amagi, Johannesburg 1989), pp. 49-63.

2. Rapp, F., "Analytical Philosophy of Technology" (Reidel, Dordrecht 1981), pp. 33-36.

3. Brown, J, S., Harvard Business Rev., Jan-Feb, 102 (1991).

4. Kiernan, M. J., "Get Innovative or Get Dead" (Random House, London 1995), p. 4.

5. Hammer, M. and Champy, J., "Reengineering the Corporation" (Nicholas Brealey, London 1993), p. 21.

6. Kealey, T., "What Risk?". (Edited by R. Bate) (Butterworth-Heinemann Publ. Co., Oxford 1997) Part IV, p. 261.

7. Vahrenholt, F., "What Risk?". (Edited by R. Bate) (Butterworth-Heinemann Publ. Co., Oxford 1997) Part IV, p. 267.

8. Badawy, M. K., Industry Week, March 20 (1989) p. 39. 